\title{
Videoconferencing As A Tool For Recruiting And Interviewing
}

Erica Baker, Jacksonville University, USA

Julius Demps II, Jacksonville University, USA

\begin{abstract}
The purpose of this pilot study is to explore opportunities for CSX, a Fortune 250 transportation company, to reduce costs associated with recruiting and interviewing potential job candidates. Videoconferencing technology has been identified as a potential method of reducing these expenses. It was discovered that recruiters at CSX were spending a great deal of time and money by traveling to universities to recruit students to work for the organization. Additionally, large sums of money were spent to bring potential job candidates to the headquarters for multiple interviews, which is located in Jacksonville, FL. This pilot study was intended to enrich the limited body of recent research as it relates to the integration of videoconferencing as a tool for interviewing. This paper was also intended to gain further insight as to how CSX could benefit through the integration of videoconferencing technology into the human resource selection process in an effort to save time and money.
\end{abstract}

Keywords: Videoconferencing, Recruiting, Interviewing

\section{INTRODUCTION}

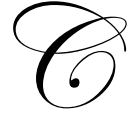

SX is a Fortune 250 company based in Jacksonville, FL. This organization owns companies providing rail, intermodal and rail to truck transload services that are among the nation's leading transportation companies. This railroad system connects more than 70 river, ocean and lake ports, as well as more than 200 short line railroads. Its principal company, CSX Transportation Inc., operates the largest railroad in the eastern United States with a 21,000-mile rail network linking commercial markets in 23 states east of the Mississippi River, the District of Columbia, two Canadian provinces and Mexico. CSX Transportation also has an employee population of approximately 36,000 (CSX, 2005).

Similar to many organizations, CSX has a large retiring population. Within the next five to ten years, approximately 60 percent of CSX's population will be eligible for retirement. In an effort to replace this portion of the population, CSX has been proactively recruiting college candidates from several universities. This involves extensive travel by company recruiters, which has resulted in significant travel expenses with such activities as scheduling, airfare, ground transportation, lodging, and meals for recruiting visits to college campuses. Hanover (2000) stated that videoconferencing can slash recruiting travel expenditures by 20 percent and also plays a part in how fast recruiters serve their clients. He also indicated that companies such as AT\&T, Dell Computer, Shell Oil, and Nike are using videoconferencing.

With such major corporations already utilizing videoconferencing equipment and with the aforementioned travel expenses within CSX, a major question that stems from this problem could be if CSX could benefit from such technology?

\section{STATEMENT OF THE PROBLEM}

CSX has exorbitant recruiting costs, which include scheduling, airfare, ground transportation, lodging, and meals for recruiters and potential job candidates. 


\section{PURPOSE OF THE STUDY}

The purpose of this pilot study will be to examine the feasibility of implementing videoconferencing technology into the human resource recruiting process at CSX Transportation, Inc. to help reduce recruiting expenditures.

\section{IMPLICATIONS}

Replacing the retiring employee population through site-based recruiting methods is an expensive process. Costs associated with this process include the following: (a) scheduling, airfare, ground transportation, lodging, and meals for recruiting visits to college campuses; and (b) airfare, ground transportation, lodging, and meals for potential job candidates from universities. It is important to note that the costs incurred when the organization facilitates visits for potential job applicants include multiple interviews. More specifically, L. Chew indicated those candidates who matriculate to finalist level will be brought to the main headquarters for second interviews, which also doubles the cost as well (personal communication, January 8, 2008). This research intends to contribute to the limited body of current research as it relates to the integration of videoconferencing technology into the human resource recruiting and selection process. This research is also designed to reduce the cost of recruiting and selection for CSX Transportation, Inc.

\section{REVIEW OF LITERATURE}

There is limited recent research that addresses the usage or effectiveness of videoconferencing technology. This factor is a primary driver of this study. A myriad of reasons exists at to why videoconferencing is becoming an integral part of business. Two major benefits associated with this process are cost and time as they relate directly to university recruiting. CSX could benchmark many organizations which already utilize videoconferencing technology to recruit college students. Brotherton (1998) determined that videoconferencing has become very popular with campus recruiters who cannot visit every school. Thompson (1999) indicated that Sprint. Corp. substituted videoconferencing for in-person recruitment of interns from Cornell University's Graduate School of Management. Before he embraced videoconferencing two years prior, he traveled 40 percent of the time, typically on short notice. Today, he spends less than 15 percent of his time traveling.

Organizations outside of college recruiting can benefit from videoconferencing technology in general. A survey of 100 telecommunications professionals in Canada, Mexico, and the United States found that $82 \%$ of companies were currently using either videoconferencing technology, undergoing trials, or planning to use it in the future (Coady et al., 1996). Thompson within (1999) is one of the nation's leading CEO headhunters. He discovered that he shortened his average four month candidate search by 25 percent and expanded his candidate pool. Bolch (2007) cited the advantages of videoconferencing as speeding up the search process, eliminating the costs of flying candidates in for interviews before finalists are selected, and reducing the time demands on applicants. Friedman (2007) stated that companies can save hours of interview time by using videoconferencing technology to narrow down their search. She also indicated that job seekers can try to impress employers without traveling for the initial interview.

Ultimately, the most critical piece of this process is to measure the costs associated with purchasing equipment and services on the front end of this process. Zaragoza (2003) says that a typical videoconference requires Integrated Services Digital Network (ISDN) phone lines and equipment. The cost is $\$ 50$ to $\$ 100$ per hour for on-premises conferencing, while offsite conferencing can cost about $\$ 225$ per hour. This can prove to be significant, depending upon the size of the organization.

\section{RESEARCH QUESTION}

The research question for the overall study is: can CSX effectively reduce the costs associated with candidate selection and recruiting from universities through the use of videoconferencing? The primary focus and research question of this pilot study is: do universities have videoconferencing technology available for student interviewing? 


\section{HYPOTHESIS}

In order to investigate the problem statement, the following hypotheses have been developed for testing.

Hypothesis: a sufficient proportion of universities have videoconferencing equipment available and either currently use it or are willing to use it for video interviewing to merit continued investigation and development of video interviewing procedures by CSX.

\section{PARTICIPANTS}

The population in this study included potential candidates from 16 Universities. CSX has already established a recruiting relationship with approximately seven of the universities in this study. In an effort to expand its candidate population pool, CSX has introduced six more universities to its database.

\section{LIMITATIONS OF THE STUDY}

This study will involve 16 universities which responded to surveys that were sent. There were 30 surveys that were distributed initially to universities east of the Mississippi River. Additionally, some of these universities my not possess the videoconferencing technology that is necessary to participate in such activity.

\section{METHODOLOGY}

The study is being conducted in two segments. The first part focuses on a cost-feasibility evaluation based on potential savings generated for CSX from videoconference interviewing implementation. The second segment focuses on the availability and utilization for virtual interviewing of videoconferencing technology at the university level.

\section{Cost Feasibility}

The implementation of cost reduction procedures within CSX are very tedious and involve the efforts employees on several levels. In the initial stage of this proposal, individuals worked closely with human resources to ensure compatibility and alignment of recruiting goals. Conference calls and meetings took place with organizational leaders to map out this process. Then a trial run was implemented to explore the costs and time associated with integrating videoconferencing as a tool to defer the costs of recruiting and interviewing potential candidates.

The management trainee team continued to visit universities throughout the year to attend career fairs and conduct interviews with students. Costs associated with this process include scheduling, airfare, ground transportation, lodging, and meals. Second round interviews involve students making site visits to the transportation company which included the same expenses at the cost of the organization. Several of these students are selected as final candidates and must make up to two trips to the company headquarters.

The final stage of this proposal involves capturing information regarding the costs associated with recruiter travel expenses and potential candidate expenses.

\section{Technology Feasibility}

A survey instrument was created and was utilized to capture data regarding the feasibility of implementing this process between CSX and the universities. Survey questions were developed and revised through joint discussion and evaluation by CSX human resources personnel and business faculty from a local university. Frequently visited and local universities were emailed a survey to measure the feasibility and interest of engaging in videoconferencing as a means of interviewing. 
The following survey was distributed:

\section{Videoconferencing Technology Usage Survey}

Do you provide online virtual-interview (webcam) capabilities that prospective employers can use to interview your students?

If so:

1. How many companies have taken advantage of this capability and interviewed your students online?

$$
0 \quad 1-5 \quad 6-10 \quad \text { More than } 10
$$

2. How long have you provided this service to students?

3. Approximately how many students have been virtually interviewed using this service at your university?

4. How often has web-based virtual interviewing contributed to subsequent employment for interviewees?

5. How do students react when interviewed online?

6. Do you believe web-based virtual interviewing has provided a significant benefit to your students? Why or why not?

If not:

1. Have any companies asked if you had these capabilities?

2. If companies who regularly attend your career fairs and seek out your students for job opportunities had them would you be more likely to implement a web camera interview system?

3. Why don't you use web-based virtual interviewing?

Cost

Too complicated

Lack of technical resources

Too impersonal

Other (explain)

4. If your university was able to overcome these issues, would you implement web-based virtual interviewing capabilities?

5. How do you believe industry can help your university overcome the issues and implement web-based virtual interviewing capabilities?

Name of school

Approximate enrollment

Person contacted

Contact phone

Contact email

Can we contact person again if needed? 


\section{DESCRIPTION OF THE VARIABLE}

\section{Dependent Variable}

The dependent variable in this study was the availability of videoconferencing tools at the universities. This included those universities that did not possess videoconferencing equipment and those who had no interest at this time.

\section{ANALYSIS OF RESULTS}

Table 1

Videoconference Technology Usage Survey Results

\begin{tabular}{lcc}
\hline & Yes & No \\
Utilizes Technology & 6 & \\
Possesses Capability and Does Not Use & 3 & 7 \\
Does Not Possess Capability & & 7 \\
\hline
\end{tabular}

As shown in Table 1 the results of the survey addressed the participation of the universities with regards to utilizing videoconferencing as a means of interviewing. Of the 16 participating universities, six currently have the tools to participate in a videoconference and either do so currently or have done so in the past. Three universities possess the capability for videoconferencing, however, they do to a lack of requests. The remaining seven universities do no possess this equipment whatsoever.

Table 2

Reasons for Not Using Web-Based Virtual Interviewing

Cost

Too Complicated 1

Lack of Technical Resources

Too Impersonal

Other (explain) ___ lack of demand, need, request, or space 7

The results from Table 2 indicate reasons why universities do not use web-based virtual interviewing. Of the 16 universities that participated in this pilot study the following reasons were cited; (a) five universities reported a lack of demand for the technology at this time; (b) two universities indicated there was a lack of space available to implement the technology; and (c) one university stated they were too far ahead of organizations when they implemented the technology and they were not as comfortable with it as they had expected. Factors such as cost, lack of technical resources, and too impersonal were not indicated by the respondents as reasons to why the universities were not utilizing the technology.

\section{CONCLUSIONS AND RECOMMENDATIONS}

For CSX to truly capture the benefits of this proposal, they would need to evaluate and implement videoconferencing technology into the recruiting and interviewing process. Based upon review of the limited literature, it would appear that it may be possible for the organization to benefit from such technology. A study on web conferencing conducted by Frost (2001) predicts the market will jump nearly 300 percent between 2005 and 2011 , to $\$ 2.9$ billion dollars. It could be assumed that with such a potential mass exodus of retiring employees that adoption of this technology could perhaps prove to be valuable in the near future.

The results of this pilot-study survey indicate that a majority of universities may currently possess videoconferencing technology. Additionally, a large majority of those universities possessing videoconferencing technology are currently using it for videoconference-based student interviews (66\%). However, of those universities who responded, the primary reason for not using video interviewing is cited as a lack of demand from 
employers. If CSX is going to capitalize on the technology, it must help create a demand within the universities where it recruits.

Continued study should focus both on the evaluation of other data collected in the survey and on expanding the number of surveyed universities to validate the analysis. It is important to evaluate responses from universities that either have but do not use or do not have videoconferencing technologies to determine why it is not being utilized. CSX has considered increasing the usage of videoconferencing technology through donating web cameras and other necessary tools for this transaction to universities. If cost is a primary driver of non-utilization of videoconferencing by universities, implementing this procedure may be beneficial for both CSX and the universities involved. It then becomes necessary to quantify corporate interviewing expenses to determine what actual cost savings would result from implementation of videoconference interviewing at CSX, which constitutes the aforementioned segment one of this study.

\section{AUTHOR INFORMATION}

Dr. Julius Demps II is an Assistant Professor of Management in the Davis College of Business at Jacksonville University. His areas of interest include Leadership, Organizational Behavior, Human Resource Management, and Principles of Management. Julius earned his Ph.D. in Organizational Leadership from Northcentral University in Prescott, Arizona.

Erica Baker is a graduate student in the Davis College of Business at Jacksonville University. Her areas of interest include Human Resources, Diversity, and Organizational Leadership. She currently serves as an intern in the human resources department at CSX in Jacksonville, FL. Erica earned her Bachelor of Science in Hospitality Management from the University of Central Florida in Orlando, Florida.

\section{REFERENCES}

1. Bolch, M. (2007). Lights, camera...interview [Electronic version]! HRMagazine, 52, 99.

2. Brotherton, P. (1998). High-tech tools shorten the job search [Electronic version]. Black Enterprise, 29, 52.

3. CSX. (2005). About CSX Coorporation. Available from CSX Web site. http://www.csx.com/?fuseaction=general.csxo_corp

4. (L. Chew, personal communication, January 8, 2008).

5. Coady, M., Gurbaxani, A., O’Brien, M., Morris, S., Prudhomme, R., \& Holz, N. (1996). Annual survey of North American telecommunications issues - 1995 survey results. New York: Deloitte \& Touche Consulting Group. In Chapman, D.S., Rowe, P.M. (2001). The impact of videoconference technology, interview structure, and interviewer gender evaluations in the employment interview: A field experiment. Journal of Occupational and Organizational Psychology, 74, 279.

6. Friedman, K. (2007). You're on: Overcoming obstacles when job interviewing by videoconference[Electronic version]. Public Relations Tactics, 14, 22.

7. Frost, M. (2001). Video interviewing: Not yet ready for primetime [Electronic version]. Bnet, 2. Retrieved January 2, 2008, from http://findarticles.com/p/articles/mi_m3495/is_8_46/ai_78132960/pg 3

8. Hanover, D. (2000). Hiring gets cheaper and faster [Electronic version]. Sales Marketing and Management, 152, 87.

9. Thompson, J.T. (1999). Dow jones and company, inc. In Lublin, J.S. (1999). Your career matters: Hunting CEO's on a 32 inch screen a recruiter uses video to search from afar. Wall Street Journal, (pg. B.1). New York: NY.

10. Zaragoza, S. (2003). Facing up to videoconferencing reality [Electronic version]. Dallas Business Journal, 27, 33. 